\title{
APOTEK PENDIDIKAN TADULAKO: IMPLEMENTASI PHARMACEUTICAL CARE SECARA PROFESSIONAL PADA LINGKUP FARMASI KOMUNITAS
}

\author{
Alwiyah Mukaddas ${ }^{\text {** }}$, Muhammad Sulaiman Zubair ${ }^{1}$, Yusriadi ${ }^{1}$ \\ ${ }^{1}$ Jurusan Farmasi, Fakultas Matematika dan Ilmu Pengetahuan Alam, Universitas Tadulako, Palu, Indonesia \\ *Penulis Korespodensi: alwiyah.mukaddas@gmail.com
}

\begin{abstract}
Abstrak
Apotek merupakan tempat dilakukan praktik kefarmasian oleh Apoteker. Apotek menjadi unit layanan kesehatan (fungsi sosial) dan unit bisnis (profit oriented). Apotek memiliki fungsi pendidikan yaitu sarana pembelajaran bagi calon tenaga teknis kefarmasian dan calon apoteker sebagai tempat praktik lapangan yang ideal menjadi nilai lebih dari Apotek Pendidikan. Selain itu, dapat menjadi tempat melakukan penelitian farmasi komunitas. Pendirian Apotek Pendidikan Tadulako (Apotek PenTa) dengan tagline LET'S TAKE A GOOD CARE OF OUR HEALTH (Caring, Serving, Learning, Educating, Being Healthy) sangat penting karena bertujuan menjadi apotek pioner yang melaksanakan implementasi peraturan pemerintah secara komprehensif dan berkesinambungan. Apotek PenTa menerapkan Branch Image Entrepreneurship yang menjalankan asuhan kefarmasian (pharmaceutical care) secara profesional dengan semboyan "no pharmacist no service". Seiring dengan itu, terpenuhinya kebutuhan masyarakat akan layanan kefarmasian yang ideal, komunikasi yang efektif serta membina hubungan melalui monitoring pengobatan akan meningkatkan customer satisfied dan customer loyality sehingga omzet apotek dapat meningkat dan profit juga akan meningkat setiap tahun.
\end{abstract}

Kata kunci: apotek pendidikan, asuhan kefarmasian, farmasis

\begin{abstract}
Pharmacy is a place where pharmacy practices are carried out. Pharmacy becomes a health service unit (social function) and business unit (profit oriented). The pharmacy has an educational function that is a learning facility for prospective pharmacy technical candidates and prospective pharmacists as an ideal field practice place to be more value than the Education Pharmacy (Apotek Pendidikan). In addition, it can be a place to conduct community pharmacy research. The establishment of the Tadulako Education Pharmacy (Apotek PenTa) with the LET 'S TAKE A GOOD CARE OF OUR HEALTH (Caring, Serving, Learning, Educating, Being Healthy) tagline is very important because it aims to be a pioneer pharmacy that implements comprehensive and sustainable government regulation. PenTa Pharmacy implements Branch Image Entrepreneurship that carries out pharmaceutical care professionally with the slogan "no pharmacist no service". Along with this, the fulfillment of the community's need for ideal pharmaceutical services, effective communication and fostering relationships through monitoring treatment will increase customer satisfaction and customer loyalty so that the turnover of pharmacies can increase and profits will also increase every year.
\end{abstract}

Keywords: apotek pendidikan, pharmaceutical care, pharmacist

\section{PENDAHULUAN}

Apotek menurut Peraturan Menteri Kesehatan Nomor 35 tahun 2014 adalah sarana pelayanan kefarmasian tempat dilakukan praktik kefarmasian oleh Apoteker. Pelayanan kefarmasian adalah pelayanan langsung dan bertanggungjawab kepada pasien (patient oriented) yang berkaitan dengan sediaan farmasi (drug oriented) dengan maksud mencapai hasil terapi yang optimal dalam meningkatkan kualitas hidup pasien. Selain itu, apotek merupakan suatu unit usaha yang dalam pelaksanaannya mempunyai dua fungsi yaitu unit layanan kesehatan (fungsi sosial) dan unit bisnis (profit oriented). Fungsi pendidikan yaitu sarana pembelajaran bagi calon tenaga teknis kefarmasian dan calon apoteker sebagai tempat praktik lapangan yang ideal menjadi nilai lebih dari Apotek Pendidikan. Selain itu, dapat menjadi tempat melakukan penelitian farmasi komunitas bagi dosen dan mahasiswa farmasi untad. Menurut Sukrasno, kompetensi tenaga kefarmasian dapat terpenuhi melalui kegiatan pembelajaran dilengkapi dengan praktik langsung di lapangan dan didukung oleh motivasi belajar mandiri secara berkesinambungan yang akan meningkatkan kepercayaan diri untuk tampil memberikan layanan profesinya (Sukrasno, 2008). 
Data Dinas Kesehatan Kota Palu tahun 2015 terdapat 161 apotek di Kota Palu yang sebagian besar $( \pm 85 \%)$ pemilik sarana apotek (PSA) non-apoteker dan hanya sebagian kecil $( \pm 12-15 \%)$ yang dimiliki oleh apoteker. Hasil survei apotek yang dilakukan tahun 2015 di Kota Palu menunjukkan bahwa hanya sekitar 2,5\% apotek yang pelayanan kefarmasian terutama praktik konsultasi, informasi dan edukasi (KIE) terapi obat pada pasien dilakukan langsung oleh apoteker termasuk di dalamnya 1,86\% (3 apotek) yang dimiliki oleh Kimia Farma. Hal ini sesuai dengan hasil penelitian Aurelia bahwa yang biasa melayani pasien di apotek adalah asisten apoteker $(48,12 \%)$, pegawai apotek $(28,30 \%)$, dan apoteker $(13,21 \%)$ (Aurelia, 2013). Data tersebut di atas menunjukkan bahwa tempat praktik lapangan yang ideal bagi calon tenaga teknis kefarmasian dan apoteker sangat sedikit sehingga peningkatan kompetensi lulusan melalui praktik kerja lapangan akan terkendala.

Apotek adalah sarana pelayanan kesehatan yang dapat ditemukan dengan mudah di wilayah Kota Palu. Universitas Tadulako berjarak sekitar $10 \mathrm{~km}$ dari pusat Kota Palu dan berada di Kecamatan Mantikulore, Kelurahan Tondo. Lokasi apotek awalnya di Jalan S. Manonda, namun lokasi dan tempat apotek tersebut tidak memadai untuk dijadikan apotek pendidikan yang akan menjadi apotek percontohan yang nantinya akan menjadi rujukan apotek di seluruh wilayah Sulawesi Tengah. Lokasi baru Apotek pendidikan yaitu berada di jalur jalan utama dan berjarak sekitar 50 m dari Rumah Sakit Pendidikan (RSP) Universitas Tadulako yang dibuka pada tahun 2017 yang masih berada di lingkungan kampus Universitas Tadulako. Selain itu, lokasi apotek pendidikan berada di kawasan padat penduduk di kelurahan Tondo, sekitar $250 \mathrm{~m}$ dari lampu lalulintas jalan trans Sulawesi Sukarno Hatta dan terdapat 4 apotek yang berjarak sekitar 1,2 km dari lokasi tersebut. Pelayanan obat di ketiga apotek tersebut tidak dikelola langsung oleh apoteker sebagai penanggungjawab apotek dan penyediaan berbagai jenis obat baik itu obat originator maupun obat generik serta alat kesehatan dan perbekalan farmasi lainnya yang masih kurang lengkap untuk setiap kondisi medis yang paling sering dikeluhkan oleh masyarakat.

Peraturan Pemerintah Nomor 51 Tahun 2009 tentang Pekerjaan Kefarmasian menyatakan bahwa pekerjaan kefarmasian adalah pembuatan termasuk pengendalian mutu sediaan farmasi, pengamanan, pengadaan, penyimpanan dan pendistribusian atau penyaluran obat, pengelolaan obat, pelayanan obat atas resep dokter, pelayanan informasi obat, serta pengembangan obat, bahan obat dan obat tradisional. Pekerjaan kefarmasian harus dilakukan oleh tenaga kesehatan yang mempunyai keahlian dan kewenangan di bidang tersebut. Peran apoteker dituntut untuk meningkatkan pengetahuan, keterampilan, dan perilaku agar dapat melaksanakan interaksi langsung dengan pasien. Bentuk interaksi tersebut berupa pemberian informasi obat dan konseling kepada pasien yang membutuhkan. Hasil survey terhadap 68 apotek di Medan menunjukkan bahwa 52,94\% apoteker pengelola apotek (APA) tidak berada di apotek setiap hari, layanan langsung pada pasien di apotek dilakukan oleh asisten apoteker $83,82 \%$, dan rerata skor penerapan Standar Pelayanan Kefarmasian di Apotek (SPKA) 47,63 termasuk kategori kurang menurut Skala Guttman (Ginting, 2008). Hasil penelitian lain yang sejalan yaitu implementasi praktik kefarmasian di farmasi komunitas yaitu pelayanan obat termasuk OTC dan obat etikal hampir semuanya dilakukan oleh asisten apoteker dan apoteker mengetahui tentang tugas dan fungsinya di apotek namun kompetensi dan waktu yang minim sampai saat ini menjadi penghalang utama penerapan PP 51 tahun 2009 (Herman, 2012). Penelitian Makadjadi di apotek Kota Palu tahun 2016 yang pelayanan kefarmasiaan dilakukan oleh apoteker menunjukkan bahwa dari 340 responden menginginkan keberadaan apoteker di apotek terdapat pada kuadran B diagram Kartesius yang harus dijaga dan ditingkatkan dan nilai Customer Satisfaction Index (CSI) 77,95\% termasuk dalam kategori Puas (Makdjadi, 2016).

Berdasarkan data tersebut diatas pendirian apotek pendidikan tadulako menjadi sangat penting karena bertujuan menjadi apotek pioner yang melaksanakan implementasi PP Nomor 51 tahun 2009 dan Permenkes Nomor 35 tahun 2014 secara komprehensif dan berkesinambungan. Tulisan ini ditujukan untuk memberikan pemaparan mengenai pendirian Apotek Pendidikan Tadulako yang diharapkan bisa menjadi salah satu apotek percontohan yang menjadi rujukan perguruan tinggi farmasi di Indonesia terutama lingkup farmasi komunitas.

\section{BAHAN DAN METODE}

Metode pendekatan yang digunakan dalam kegiatan ini berupa studi kelayakan pendirian usaha apotek meliputi:

1) Bahan Baku, Pengadaan obat sebagai komoditas utama diperoleh dari pedagang besar farmasi (PBF) resmi yang ada di Kota Palu. Jumlah PBF skala nasional di Kota Palu cukup banyak sehingga ketersediaan dan mutu obat akan terjaga. Penyediaan alat kesehatan dan perbekalan farmasi lainnya akan diperoleh dari distributor alat kesehatan yang berizin baik itu yang berada di kota Palu atau kota lain sekitarnya seperti Makassar yang memiliki jalur transportasi pengiriman barang yang mudah dan terpercaya. 2) Produksi, Apotek sebagai unit usaha yang berbadan hukum maka setiap peralatan, sarana dan prasarana yang harus disediakan telah diatur jumlah dan jenisnya sesuai Kepmenkes No. 1332 tahun 2002 tentang ketentuan dan tata cara pemberian izin apotek (semua sarana dan prasarana dalam kondisi baru). 3) Proses produksi, Proses pengadaan dan penjualan obat (Resep dan Non-resep) sebagai komoditas utama di apotek sesuai protap (prosedur tetap). 4) Manajemen, struktur organisasi Apotek Pendidikan Tadulako. 5) Pemasaran, Letak/lokasi apotek pendidikan strategis karena berjarak sekitar 50 $\mathrm{m}$ dari rencana Rumah Sakit Pendidikan, berada tepat di pintu keluar kampus untad yang terdapat di 
pemukiman penduduk termasuk di dalamnya kompleks dosen untad dan sekitar 10 kompleks perumahan lain yang juga bertambah jumlahnya setiap tahun. Apotek pendidikan berada di daerah dengan kepadatan penduduk yang cukup tinggi di Kelurahan Tondo \pm 9.892 KK (Kepala keluarga), juga menyasar seluruh civitas akademika Universitas Tadulako sekitar \pm 32.000 orang. Selain itu, fasilitas umum seperti kantor Kelurahan Tondo dan Sekolah Tinggi Kesehatan Widya Nusantara yang juga berpotensi besar menjadi konsumen apotek pendidikan. 6) Sumber daya manusia (SDM) Pengelolaan apotek sebagai unit usaha penghasil keuntungan harus efektif dan efisien agar tujuan apotek tercapai dengan optimal. Apotek pendidikan mempekerjakan 4 karyawan yaitu Apoteker Pengelola Apotek (1 org) dan tenaga teknis kefarmasian (3 orang).

\section{HASIL DAN PEMBAHASAN}

Berdasarkan implementasi Program Pengembangan Usaha Produk Intelektual Kampus (PPUPIK) Apotek Pendidikan Tadulako yang bertujuan untuk mendirikan unit usaha milik Universitas Tadulako yang diawasi langsung oleh Jurusan Farmasi, Fakultas Matematika dan Ilmu Pengetahuan Alam. Tujuan utama pendirian Apotek Pendidikan Tadulako (PenTa) adalah apotek pioner yang melaksanakan implementasi PP Nomor 51 tahun 2009 dan Permenkes Nomor 35 tahun 2014 secara komprehensif dan berkesinambungan. Apotek PenTa memiliki tiga fungsi yaitu fungsi pendidikan, fungsi bisnis/profit, dan fungsi sosial. Fungsi pendidikan sebagai tempat praktik lapangan bagi mahasiswa S1 (strata 1) Jurusan Farmasi dan calon apoteker. Selain itu, menjadi tempat penelitian dosen dan mahasiswa bidang farmasi komunitas. Fungsi profit sebagai unit usaha yang memberikan keuntungan bagi perkembangan apotek itu sendiri dan pemasukan bagi universitas tempat bernaung. Fungsi sosial berupa layanan konsultasi dan Pusat Informasi Obat (PIO) yang up to date bagi masyarakat dan tenaga kesehatan lain. Saat ini apotek telah dibuka untuk umum (soft opening) sejak tanggal 1 Juli 2018 karena telah memenuhi syarat dari Dinas kesehatan Kota Palu yang dibuktikan dengan keluarnya berbagai perizinan yaitu Surat Izin Praktik Apoteker (SIPA), Surat Izin Apotek (SIA), dan Surat Izin Usaha Perdagangan (SIUP). Proses renovasi dan persiapan sarana dan prasarana apotek membutuhkan waktu yang cukup lama dan dilakukan secara bertahap karena gedung harus disesuaikan dengan syarat yang ditentukan oleh aturan perundang-undangan tentang apotek (Gambar 3.1; 3.2; $3.3 ; 3.4 ; 3.5 ; 3.6 ; 3.7 ; 3.8)$.

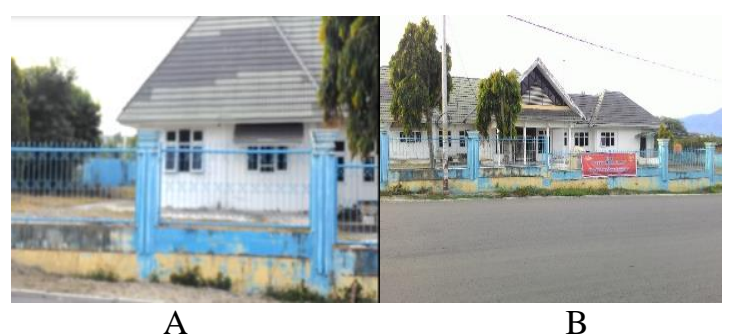

Gambar 3.1 Klinik dan apotek sebelum renovasi (A), Apotek sebelum renovasi (B)

Apotek terletak di depan Rumah Sakit Pendidikan (RSP) Tadulako, yang sebelumnya berfungsi sebagai Kantor Otoritas Pelabuhan Penyeberangan Kementerian Perhubungan Provinsi Sulawesi Tengah. Apotek Pendidikan Tadulako memiliki 4 karyawan yaitu satu Apoteker Pengelola Apotek (APA), 3 orang tenaga teknis kefarmasian/ Asisten Apoteker (AA). Apotek memiliki jadwal operasi senin sampai dengan sabtu, sejak jam 08.00 a.m sampai jam 09.00 p.m, terbagi atas dua shift kerja.

Apotek PenTa memiliki logo yang didominasi oleh warna hijau yang bermakna sehat/kesehatan (Gambar 3.9) dengan tagline "let's take a good care of our health": caring, serving, learning, educating, being healthy. Logo dan tagline akan menjadi brand image Apotek PenTa.

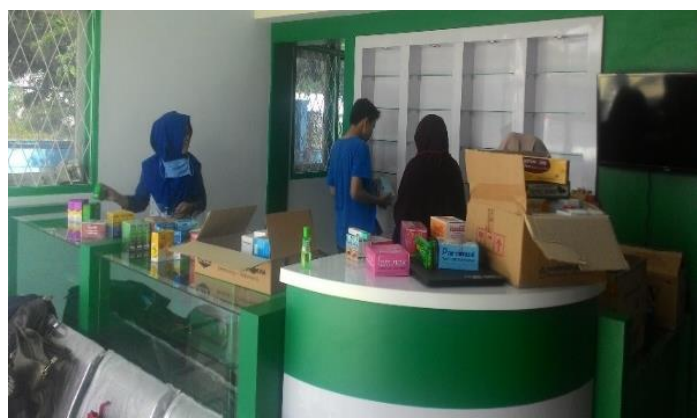

Gambar 3.2 Karyawan apotek mulai melakukan pembelian obat

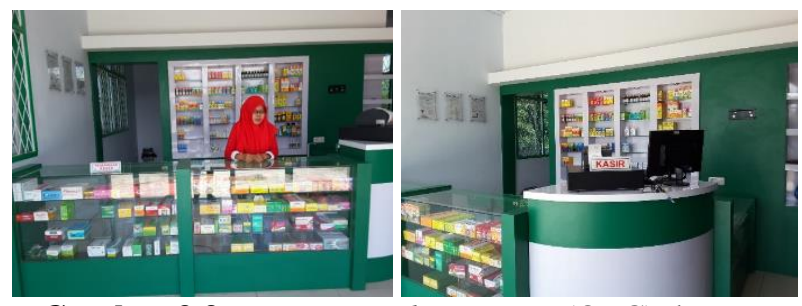

Gambar 3.3 Ruang over the counter (OTC) depan dan Kasir depan

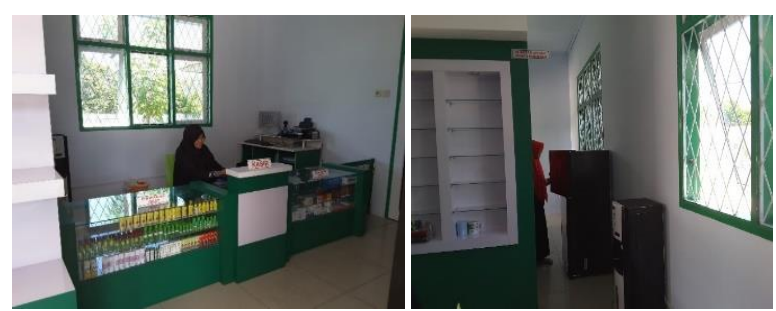

Gambar 3.4 Ruang OTC samping, penerimaan resep, penyerahan obat, dan kasir klinik 


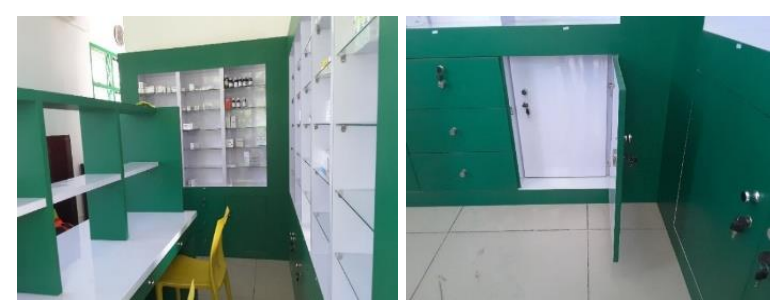

Gambar 3.5 Ruang pelayanan resep (ruang racik) dan lemari narkotika psikotropika

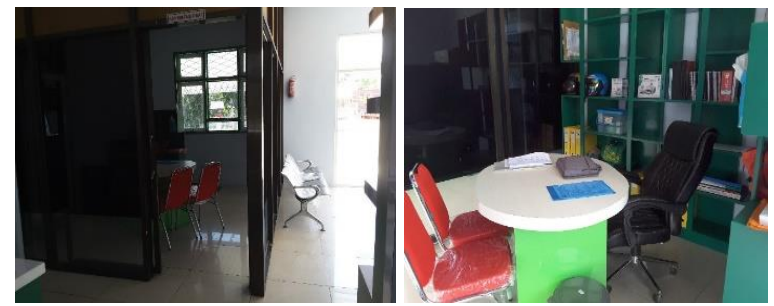

Gambar 3.6 Ruang konsultasi obat

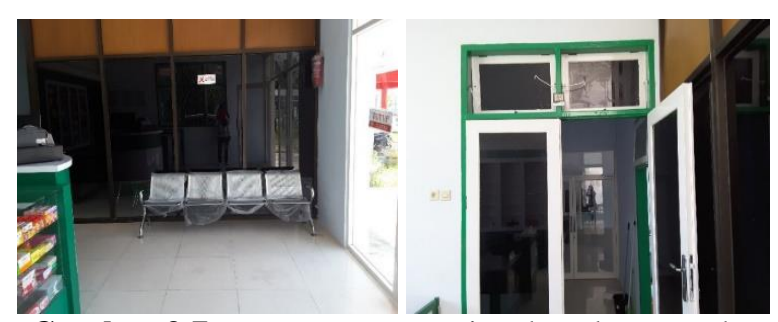

Gambar 3.7 Ruang tunggu pasien dan alat pengukur suhu dan kelembapan ruangan

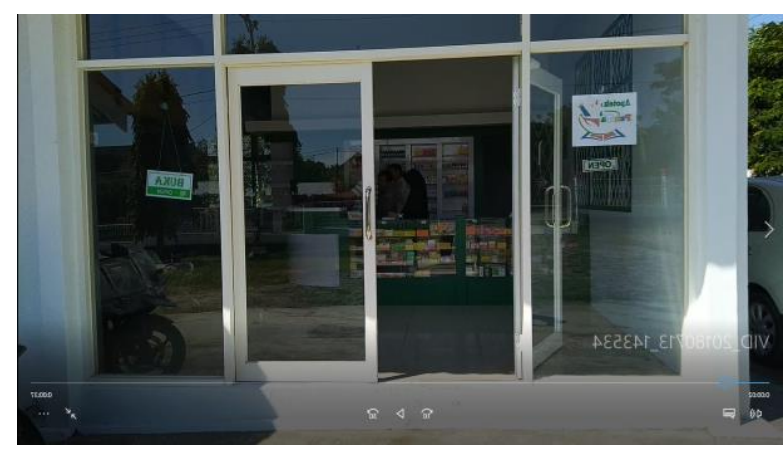

Gambar 3.8 Apotek tampak depan setelah renovasi bertahap

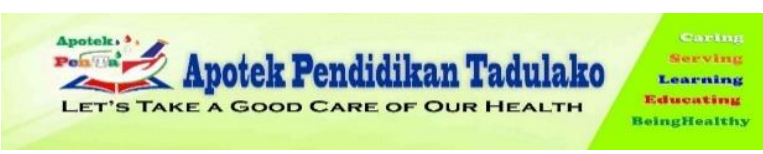

Gambar 3.9 Logo dan tagline Apotek Pendidikan Tadulako

Berdasarkan hasil implementasi kegiatan PPUPIK, diperoleh hasil sebagai berikut: 1) Apotek Pendidikan Tadulako (PenTa) telah dibuka dengan standar sarana prasarana sesuai persyaratan PP Nomor 51 tahun 2009 dan Permenkes Nomor 35 tahun 2014. 2) Melakukan pelayanan penjualan obat dan konsultasi obat ke masyarakat.

\section{KESIMPULAN}

Apotek Pendidikan Tadulako bertujuan menjadi apotek pioner yang melaksanakan implementasi PP Nomor 51 tahun 2009 dan Permenkes Nomor 35 tahun 2014 secara komprehensif dan berkesinambungan. Apotek Pendidikan Tadulako akan menjadi salah satu apotek percontohan yang menjadi rujukan perguruan tinggi farmasi di Indonesia terutama lingkup farmasi komunitas.

Program PPUPIK Apotek Pendidikan Tadulako telah menambah pengetahuan dan pengalaman empirik tentang pelayanan kefarmasian di komunitas bagi tim pelaksana kegiatan PPUPIK. Kesimpulan yang diperoleh dari uraian di atas adalah sebagai berikut:

1) Apotek Pendidikan Tadulako (PenTa) adalah unit usaha Jurusan Farmasi, FMIPA, Universitas Tadulako.

2) Apotek PenTa menjadi apotek pendidikan pionir di Kota Palu, Sulawesi Tengah.

3) Apotek PenTa dengan tiga fungsi yaitu pendidikan, bisnis/profit, dan sosial.

Berdasarkan uraian dan kesimpulan tersebut di atas maka tim pelaksana PPUPIK mengusulkan beberapa aspek sebagai berikut:

1) Program PPUPIK harus tetap diadakan untuk menjadi apotek percontohan di Sulawesi Tengah yang melaksanakan PP Nomor 51 tahun 2009 dan Permenkes Nomor 35 tahun 2014 secara komprehensif dan berkesinambungan.

2) Program PPUPIK akan membuat Sistem Informasi Manajemen (SIM) yang terintegrasi dengan Klinik Tadulako Medical Center.

3) Program PPUPIK akan membuat satelit apotek pendidikan agar jangkauan masyarakat lebih luas.

4) Program PPUPIK di akhir kegiatan bisa menjadi unit usaha yang memberikan pemasukan bagi universitas.

\section{UCAPAN TERIMA KASIH}

Terima kasih disampaikan kepada: 1) Direktorat jenderal pengabdian masyarakat Kementerian Ristek dan Dikti Republik Indonesia, 2) Pimpinan dan seluruh staf Lembaga Penelitian dan Pengabdian masyarakat Universitas Tadulako, 3) Dekan dan seluruh staf Fakultas MIPA, UNTAD. 4) Dekan dan seluruh staf Fakultas Kedokteran, Universitas Tadulako, 5) Direktur dan seluruh staf Rumah Sakit Pendidikan Universitas Tadulako. 6) Tim pelaksana dan mahasiswa Jurusan farmasi, FMIPA, Universitas Tadulako. Semoga hasil kegiatan pengabdian ini mampu memberikan manfaat jangka panjang bagi kalangan farmasi komunitas, Universitas Tadulako, dan seluruh masyarakat Kota Palu, Sulawesi Tengah.

\section{DAFTAR PUSTAKA}

Aurelia, E. (2013). Harapan dan kepercayaan konsumen Apotek terhadap peran Apoteker yang berada di wilayah Surabaya Barat. Calyptra: Jurnal Ilmiah Universitas Surabaya. Vol.2 No.1.

Dinas Kesehatan Kota Palu. (2015). Rekapitulasi Jumlah Apotek di wilayah Kota Palu tahun 2015. Palu, Sulawesi Tengah: Dinas Kesehatan Kota Palu. 
Ginting, A., Br. (2008). Penerapan Standar Pelayanan Kefarmasian di Apotek Kota Medan Tahun 2008. Skripsi. Universitas Sumatra Utara. Medan.

Herman, M., J., \& Susyanty, A., L. (2012). An analysis of Pharmacy Service By Pharmacist In Community Pharmacy. Buletin Penelitian Sistem Kesehatan. Vol.15 No.3, p.271-281

Ketentuan dan Tata Cara Pemberian Izin Apotik 2002 (Kepmenkes) Nomor 1332 (RI)

Makadjadi, O.I., Mukaddas, A., Tandah, M.R. (2016). Analysis of The Patient Satisfaction Level to Pharmacist Service Quality in Four Pharmacies in Palu City using Servqual Method. Proceedings International Conference and workshop on Pharmacy and Statistics, 26-27 November 2016. Palu, Sulawesi Tengah. Hal. 99-108

Pekerjaan Kefarmasian 2009 (PP) Nomor 51 (RI)

Standar Pelayanan kefarmasian di Apotek 2014 (Permenkes) Nomor 35 (RI)

Sukrasno. (2008). Pengembangan pendidikan profesi apoteker untuk mendukung eksistensi apoteker di apotek. Majalah Ilmu Kefarmasian, vol. V, No. 3, pp.130-137. 